\title{
Michael Vick’s Pit Bulls \& Dogfighting: Ramifications of Media Coverage
}

\author{
Rebecca Crinean Pickens ${ }^{\mathrm{a}}$
}

According to The Humane Society of the United States, from 2006 to 2008 there were more than 3,000 pit bulls removed from dogfighting rings. The majority of surviving dogs were euthanized upon confiscation by authorities. The purpose of this research was to examine the possible impact of Michael Vick's dogfighting case on print media coverage of pit bull-type dogs. The research questions were whether the extensive coverage of his dogfighting charges would change how media portray these dogs, and whether the issue of dogfighting would become a more widely covered topic. The research process included a literature review of scholarly works written about pit bull-type dogs and a qualitative analysis of articles from The New York Times, The Wall Street Journal, and USA Today published one year before and after the Vick case broke, using "pit bull" as the key search phrase. Articles were divided into different categories depending on the contextual use of the term "pit bull." Findings were based on the analysis of those categories. The results indicated positive portrayals of pit bulls and discussions of dogfighting were primarily isolated to the coverage of Vick's case and dogs. The more than 200 other recorded raids on dogfighting rings that same year went unmentioned, but six stories about aggressive behaving pit bull-type dogs were published. This indicates media coverage of this body of dogs did not change. Media can learn there is more to cover than limiting the focus on celebrity dogfighters and the cliché of pit bull-type dogs as vicious. These changes in coverage could lead to an overall positive change in the public's perception of this greatly misunderstood group of dogs called "pit bulls."

Keywords: Pit Bull-Type Dogs, Michael Vick, Dogfighting

\section{Introduction}

The relationship between pit bull-type dogs and the media is complicated. While the exact genesis of the hysteria surrounding what was once hailed the "all-American dog" cannot be determined, the media are often cited as a primary cause of their infamy. An example of how influential popular print media has been regarding this issue is the July 1987 Sports Illustrated cover story "The Pit Bull Friend and Killer: Is the Pit Bull a Fine Animal, As Its Admirers Claim, Or Is It a Vicious Dog, Unfit for Society" by Swift (1987). The article is believed by some to be a contributing factor for the public's fear of these dogs, "Unfortunately the pit bull, when it attacks, doesn't merely bite man-or, most horribly, child- it clamps its powerful jaws down and literally tears its victim apart" (Swift, 1987). The magazine's cover shot is a closeup of a snarling pit bull-type dog with the text "Beware of this Dog" boldly across the front. The August 2000 cover of Sports Illustrated celebrated Atlanta Falcons' quarterback Michael Vick as "Mr. Electric," ("Mr. Electric: Why Michael Vick of Virginia Tech Has Sparked A Revolution at Quarterback," 2000). The dark irony of that title would be revealed with his arrest in 2007.

A drug raid at Vick's Surry County, Virginia home uncovered his underground dogfighting ring, Bad Newz Kennels. The authorities rescued 66 dogs from the property, 55 of them pit bulls ("Penalties are More Severe," 2007). "Mr. Electric" was found to have electrocuted, shot, and hung dogs that did not perform well in his organized dogfights ("Falcons' Vick Indicted by Grand Jury in Dogfighting Probe," 2007). For the first time in decades America rallied for the pit bull. Animal rights advocates saw an opportunity to increase public demand for tougher sentencing on dogfighting ("A Catalyst for Change," 2007) and decrease public fear of these misunderstood dogs.
While the coverage of the Vick case and the rehabilitation of the dogs rescued from his property consumed media coverage through 2007, the long-term ramifications of the Vick case on the public perception of pit bull-type dogs has yet to be examined. As noted by Gorant (2010), the opportunity to learn from the Vick case can diminish without any change as the novelty fades:

The phrase of choice has been 'moving on.' As in 'Michael's moving on' or 'People have moved on' or 'It's time to move on.' It's a euphemism that can be roughly translated to mean, 'Can't we just forget all that stuff and talk about football?' Well, no. There has to be a way to reconcile these two positions, to join the past to the present (p. 16).

But how long will the weight of the Vick case drive the public's demand of justice for fighting dogs? How long will pit bull-type dogs be seen in the public's mind as more often victims of a stereotype than perpetrators? Does the compassion expressed for Vick's dogs extend to pit bull-type dogs as a whole?

The purpose of this research is to seek answers to those questions by examining newspaper coverage of stories involving dogs labeled as pit bulls before and after the Vick case. The hypothesis is that the dogs rescued from Vick's property will be written about in a positive light, while stories involving pit bull-type dogs not related to his case will continue to have negative connotations, or not be mentioned at all.

To understand the topic fully, a literature review has been conducted of scholarly essays, newspaper and magazine articles written from 2000 to 2010 using "pit bull," "dogfighting," and "Michael Vick" as key search terms. A time frame of 2000 to 2010 was selected to give a multipleyear space before and after the Vick case to allow for changes in coverage of pit bull-type dogs to become evident. There 
are only 13 scholarly articles written on the topics of pit bulltype dogs and dogfighting during this time frame. They include studies on sympathy toward fighting dogs, media influence on public distrust of pit bull-type dogs, how owners cope with the stigma of their dogs as dangerous, and a study of differences in aggression among breeds.

"Sympathetic Reactions to the Bait Dog in a Film of Dog Fighting: The Influence of Personality and Gender" by Lee, Gibbons, and Short (2010) is the only research study developed as a direct result of the of the Vick case. While the study made no comment pertaining to implications on media coverage of pit bull-type dogs in the news, a conclusion could be drawn based on their findings that the majority of the public is sympathetic toward abused animals, even pit bulls, as indicated by the outrage over the abuse the Vick dogs experienced.

\section{Media's Portrayal of Pit Bull-Type Dogs}

A search on media coverage of pit bull-type dogs and its effect on public opinion yielded only one article by Cohen and Richardson (2002) entitled "Pit Bull Panic." The study was conducted five years before the Vick raid and thus bears no relevance on how the case influenced news coverage of this group of dogs. However, Cohen and Richardson (2002) placed blame on the media for portraying a negative image of pit bull-type dogs without using credible sources or journalistic integrity (p. 290).

Cohen and Richardson conducted a survey yielding enlightening results regarding media influence on public perception of rehabilitating fighting dogs. The survey showed most people distinguished between media portrayal of pit bull-type dogs as inherently dangerous and the fact that all dogs are individuals with distinct personalities and temperaments. However, those surveyed believed dogs used in dogfighting should be euthanized, and not evaluated on an individual basis (Cohen and Richardson, 2002, p. 308). These results are interesting in light of the overwhelming public outcry to save the Vick dogs from euthanasia, despite the widely held belief by much of the public that dogs labeled as pit bulls are unsafe for society.

The 2001 study by Twining, Arluke, and Patronek (2001), "Managing the Stigma of Outlaw Breeds: A Case Study of Pit Bull Ownership" addresses the way owners of pit bull-type dogs deal with the stigma that their dogs are dangerous. The authors interviewed 28 owners who had adopted a pit bull-type dog in the past year and a half regarding their experience. The study revealed that many of the owners interviewed believed that inflammatory media portrayal had influenced public fear of their dogs (Twining et al., 2001, p. 15), indicating a perceived need for reform of media coverage of pit bull-type dogs.

Twining et al. (2001) interviewees indicated most people who expressed concern over their choice to own a pit bulltype dog based their fears around believed "viciousness and lack of predictability" (p. 4) in these dogs' temperament. Results of the study showed that debunking adverse media coverage was one of the most commonly used coping mechanisms by owners to handle accusations that their dogs were dangerous (Twining et al., 2001, p. 5). The researchers found most owners listed selective reporting, sensationalism, lack of objectivity, and failure to provide context as the primary problems behind media coverage of pit bulls (Twining et al., 2001, p.15).

Their article does not go on to examine the reasons why media portray these dogs in an unbalanced light. But the fact that debunking media-propagated myths was a common tactic of pit bull-type dog owners indicates a need for further examination of media responsibility and whether the Vick case changed national print coverage.

Duffy, Hsu, and Serpell's (2008) article "Breed Differences in Canine Aggression" examined reports of aggressive behavior divided by specific breeds from breed club statistics and an online survey of dog owners (p. 4). In their research Duffy et al. (2008) use the term "pit bull" and "Pit Bull Terrier" as the name of a specific breed. The accurate, historical definition of "pit bull" is a nickname used for three breeds: the American Staffordshire Terrier, American Pit Bull Terrier (not recognized by the American Kennel Club) and the Staffordshire Bull Terrier. The term "pit bull" by itself is not an official breed name. But this label is commonly used today by media, owners, animal care professionals and the public for any dog (often of unknown pedigree) that has certain physical characteristics. Therefore dogs labeled as "pit bulls" fall into a huge category of various mixes of many different breeds, and frequently have no shared DNA (Olsen, Levy and Norby, 2012). This is an important point as it emphasizes that much of the research about these dogs has been shrouded in confusion.

The study found that while dogs included under their label of the breed "pit bull" did show higher levels of aggression toward unknown dogs, their aggression toward unfamiliar people was only $2.3 \%$ above average when compared to the other breeds examined (Duffy et al., 2008, p.15-16). The dogs this study identifies as pit bulls were ranked average in incidents of aggression toward owners, while breeds including Basset Hounds and American Cocker Spaniels were ranked high for owner directed aggression (Duffy et al., 2008, p.15). Duffy et al. (2008) noted dogs labeled as pit bulls in their study had relatively low scoring for human aggression contradicting the widespread belief that dogs defined by this term are inherently vicious (p.15), a belief for which media is often considered largely responsible by advocates for spreading.

\section{Books}

In the last 10 years, few books have been written pertaining to pit bull-type dogs. The majority of trade publications are owners' guides. Two that address the cultural issues surrounding pit bull-type dogs are The Pit Bull Placebo: The Media, Myths and Politics of Canine Aggression by Delise (2007) and American Pit Bull Terriers Fact or Fiction: The Truth Behind One of America's Most Popular Breeds by Capp (2004). Both books seek to debunk the widespread sensational myths surrounding them including that they have locking jaws, a propensity to turn on owners, and their brain grows too fast for their skulls causing aggression (Capp, 2004, p. 83-87).

Capp (2004) states the media has influenced public fear with "overzealous reporting" (p. 33), while ignoring attack stories involving other types of dogs. Delise (2007) noted that in the 1970s coverage of a string of dogfighting raids brought special attention to pit bull-type dogs by the media, 
but with the high coverage of the fighting dogs came the propagation of myths such as the locking jaw (p. 95-96) the outcome of which was fear and misunderstanding about dogs that should have received compassion as victims of a cruel blood sport.

While both books were written before the Vick case broke, the authors' arguments provide a good basis to measure whether popular print media has changed its tactics since Vick.

\section{Coverage of the Vick Case}

At the time this research was conducted no scholarly articles have been written about the Vick case or its effect on media coverage of pit bull-type dogs. However, there are hundreds of articles covering his case in popular culture outlets. The majority of the articles are from trade publications such as USA Today, The New York Times, Sports Illustrated, and DVM. Most of the articles cover the Vick trial and his future prospects in the NFL. Of the articles not strictly pertaining to case details, many centered on whether Vick had been punished harshly enough for his crimes (Weingarten, 2009, p. A12).

Along with discussions on Vick's punishment were articles questioning why the NFL was treating animal cruelty by players with more severity than domestic violence by professional sports players (Sandomir, 2007, p. D5). In addition to social issues, the topic of what to do with rescued fighting dogs was a frequent debate in articles pertaining to his case. Some national animal welfare organizations believed euthanasia was the most humane option due to the unique challenges of rehabilitation and adoption of fighting dogs available at the time (Schmidt, 2007, p. D1), while others disagreed and sought rehabilitation options for the dogs (Gorant, 2008, p. 72, 77). The few articles not discussing the Vick case primarily dealt with legislation on dogfighting issues along with a few on pit bull-type dogs and stereotyping.

\section{Summary of Literature Review}

The scholarly articles addressed in this literature review reveal a void in academic research pertaining to the effect of the Vick case on public perception of pit bull-type dogs and dogfighting. No academic research has been conducted as to whether the Vick case has changed the coverage of pit bulltype dogs in news stories. At the time this research was conducted the only study examining these dogs from a communication perspective is Cohen and Richardson's (2002) article "Pit Bull Panic," but this article had a significant flaw in the credibility of a source. Cohen and Richardson (2002) quote Richard Stratton as one of the foremost authorities on pit bulls (p. 291). Richard Stratton is a dogfighting enthusiast, so the choice to quote Stratton in a paper advocating for pit bull-type dogs begs the question regarding their sources.

The lack of scholarly research on the issues of media portrayal of pit bull-type dogs and dogfighting shows there is room to expand common knowledge about these controversial topics. The goal of this study is to contribute to the body of research by conducting a qualitative content analysis of print media coverage of stories involving pit bull-type dogs before and after the Vick case.

\section{Methodology}

This research focuses on whether reports of Vick's dogfighting case changed how print media portray pit bulltype dogs. A qualitative study was conducted of national newspaper publications using the word "pit bull" as the search term. Qualitative research method was used as this study looked at primarily non-numerical data examining the context in which pit bull-type dogs were placed when included in print stories. The purpose of this research was to identify any underlying ideologies presented about this group of dogs based on the content of the stories written involving them. Research examined articles written one year before the Vick case and one year after. The choice to use a two-year time frame was to garner a year's worth of stories to determine how print media covered these dogs immediately before the Vick case, and directly after the case to gauge any change.

National publications were chosen because they are most read by the general public regardless of location. While there are many more stories pertaining to pit bull-type dogs in local newspapers, they primarily affect the perception of regional readers. The publications examined were The New York Times, The Wall-Street Journal, and USA Today. From April 25, 2006 to April 25, 2008 the search yielded a total of 54 articles with the term "pit bull" in the text. There were 25 articles written before the Vick case, and 29 written after. Each article was placed into specific categories based on the context of the stories.

\section{Categories}

Below is a description of the 13 categories that emerged from the text with examples to illustrate.

\section{Advocacy}

Articles in the "Advocacy" category discuss animal rights groups who rescue or advocate for pit bull-type dogs. Vitello's (2006) article in The New York Times presents an excellent example of an article in the "Advocacy" category, "The underfed pit bull puppies were not the worst case they had come upon in two years of running what some call their soup kitchen for dogs."

\section{Aggression}

Articles about dogs identified in the story as pit bulls that had shown aggression by attacking or biting a person or animal were put in this category. The New York Times story "Pit Bull Bites Officers" (2006) is an example of the types of story in this category "...a pit bull attacked one of them, biting him on the leg..."

\section{Breed Specific Legislation (BSL)}

Articles discussing legislation banning breeds and types of dogs deemed dangerous, often including pit bull-type dogs, were categorized into the "Breed Specific Legislation" category. The New York Times story, "Pit Bull Owners Put Laws to the Test," by Whitaker (2006) discuss breed specific legislation, "When Natalie Wells bought a home in Englewood, N.J., a year ago, she was unaware that her American pit bull terrier was illegal to own in the city" (p. L14). 


\section{Crime/Legal}

Pit bull-type dogs included in articles where crimes or convictions of crimes other than animal cruelty or dogfighting are discussed, "In 2004, after Pittman pleaded guilty to one felony count and served 14 days in jail, the NFL suspended him..." ("In Handling Abuse Cases, NFL Mirrors Society," 2007, p. A12).

\section{Cruelty/Neglect}

Stories where pit bull-type dogs were victims of a form of animal abuse other than dogfighting as in Sullivan's (2006) article in The New York Times, “...Mr. Guy's three other dogs were emaciated when they were found."

\section{Description}

Articles in which the term "pit bull" was used to describe a person or as a metaphor, often in regards to being aggressive as in Kuczynski's (2006) piece in The New York Times, "...the edge of autumn has bitten in and holds on like a pit bull with a bad temper."

\section{Dogfighting}

Articles where pit bull-type dogs were mentioned in connection with dogfighting cases, but do not mention the Michael Vick case as in Barnes' (2006) article in "Texas: Judge Orders 225 Pit Bulls Killed."

\section{Euthanasia of Fighting Dogs}

Articles that discuss the euthanasia of dogs used to fight as discussed in Barnes' (2006) piece, “A justice of peace in Cleveland...ordered the destruction of 225 pit bulls that the authorities said had been bred for fighting."

\section{Family Pet}

Pit bull-type dogs in these articles are portrayed as loved members of the family as in this example from Santos' (2006) article, "'I'm upset a member of my family was killed', said Mrs. Franco who brought the dog into her home as a puppy..." (p. B3).

\section{Machismo Culture}

Stories where pit bull-type dogs are mentioned as pets of those involved in gangster culture, the rap/hip hop music industry, or as status symbols of masculinity. The following excerpt gives an example of this category from Roberts' (2007) story in The New York Times, "As the trendiest badboy accessories, the pit bull is the new gun for some players."

\section{National Football League (NFL)}

Stories where NFL players are connected to pit bull-type dogs as in Roberts' (2007) article, “The league's pet problem is the unseemly ties of gambling and gang symbols with the dog-fighting ethos."

\section{Police Shootings}

This category consisted of articles in which police were reported to have shot pit bull-type dogs, "Three officers were grazed by bullets yesterday morning, when the police fired more than two dozen shots at a pit bull that had locked its jaw around a fourth officer's leg..." (Santos, 2006, p. B3).

\section{Vick Case}

All articles that mention the Michael Vick dogfighting case are put into this category.

\section{Results}

\section{Pre-Vick Results}

From April 25, 2006 to April 25, 2007, there were a total of 25 articles in The New York Times and USA Today that included the term "pit bull." An examination of The Wall Street Journal archives produced no results in the year leading up the dogfighting raid on Michael Vick's property. The following chart shows the category breakdown of articles using the term "pit bull" in the text (most articles fell into multiple categories):

\begin{tabular}{lc}
\hline Category & Number of Articles \\
\hline Advocacy & 4 \\
Aggression & 5 \\
BSL & 2 \\
Crime/Legal & 3 \\
Cruelty/Neglect & 3 \\
Description & 8 \\
Dogfighting & 3 \\
Euthanasia- & 2 \\
Fighting Dogs & \\
Family Pet & 5 \\
Machismo Culture & 2 \\
NFL & 2 \\
Police Shootings & 2 \\
\hline
\end{tabular}

The largest category using the term "pit bull" was "Description" with a total of eight articles. The majority of articles used the term as an adjective describing an aggressive or ill-tempered person. Brantley's (2006) article in The New York Times reviewing a Broadway play is an example of the negative connotations presented, "Like some crazy mixed-up house pet- part pit bull, part lap dog - the Broadway musical has taken to biting and licking simultaneously the hand that feeds it." This statement brands pit bull-type dogs as unsuitable as loving pets because of an alleged aggressive disposition.

"Pit bull" was also a popular term to describe unpleasant political figures and tenacious athletes. Leibovich's (2006) article in The New York Times entitled "Pit Bull Of the House Latches On to Immigration," quotes a Senate representative describing Representative F. James Sensenbrennar in the following manner. "Sensenbrennar is a pit bull. And the Senate negotiators he's up against are wearing milk bone underwear" (p. A1). Other terms in the article describing Representative Sensenbrennar were "prickly," "cantankerous," and "unpleasant," (Leibovich, 2006, p. A1) connecting the term "pit bull" to anti-social personality traits. In sum there were no descriptions using the term "pit bull" within a positive context.

The second largest categories identified were "Family Pet" and "Aggression." There were five articles in both of these categories. There were only four articles in the "Advocacy" category and three articles each in the categories "Crime/Legal," "Cruelty/Neglect," and "Dogfighting" in the year before Vick's case. Only one of the three articles in the "Dogfighting" category covered a raid of a dogfighting ring. 
Barnes' (2006) article, "Texas: Judge Orders 225 Pit Bulls Killed" is a brief article on a ruling to euthanize fighting dogs taken from a dogfighting ring. This raid, which was three times the size of Vick's operation, was only mentioned one other time in the introduction for Jones' (2006) article.

\section{Post-Vick Results}

From April 25, 2007, the day the Michael Vick case broke, to April 25, 2008 there were 29 articles that specifically used the term "pit bull" in their text from The New York Times, The Wall Street Journal, and USA Today, 22 referenced Vick directly. The following chart shows the category breakdown of articles using the term "pit bull" in the text (most articles fell into multiple categories):

\begin{tabular}{lc}
\hline Category & Number of Articles \\
\hline Advocacy & 11 \\
Aggression & 6 \\
BSL & 1 \\
Crime/Legal & 7 \\
Cruelty/Neglect & 4 \\
Description & 0 \\
Dogfighting & 9 \\
Euthanasia- & 6 \\
Fighting Dogs & \\
Family Pet & 1 \\
Machismo Culture & 1 \\
NFL & 6 \\
Police Shootings & 1 \\
Vick & 22 \\
\hline
\end{tabular}

The largest category of articles using the term "pit bull" was the "Vick" category in which there were 22 articles. The articles ranged from stories that covered the care for his dogs (Macur, 2008), and stories that documented his fall from grace (Mihoces, 2007). The other stories in this category discussed Vick's case in relation to the increase of dogfighting raids, like Koch's (2007) article, and other pit bull-type dog related issues in the NFL as in Roberts' (2007) article, "In Sports, Unleashing the Dogs that Abhor."

The second largest categories were "Advocacy" with 11 articles, followed by "Dogfighting" with nine stories. All the stories in the category of "Advocacy" and the category of "Dogfighting" were covered exclusively in context of the Vick case. No other dogfighting raids were covered in the year after the Vick case.

The most significant change in coverage of pit bull-type dogs in the year after the Vick case was the absence of the term "pit bull" as a negative description. In the Pre-Vick Results this was the largest category, but it completely disappeared from use in the publications examined in the year following.

\section{Research Summary}

The year before the Vick case broke, media reference to pit bull-type dogs, though seldom, was primarily negative. The greatest usage of the term "pit bull" was to describe something nefarious. The frequent abuse of these dogs in dogfighting was practically a non-existent topic.
In the year following the raid on Vick's property, articles using the term "pit bull" were dominated by stories covering his case. There was no coverage of raids on any other dogfighting rings. The topic of pit bulls consigned to dogfighting and advocacy for them were not covered without mentioning Michael Vick. The most significant change in media coverage of pit bull-type dogs in the year following Vick's arrest was the movement away from the use of the term "pit bull" as a synonym for aggression.

\section{Discussion}

These findings indicate that positive coverage of pit bulltype dogs after the Vick's arrest was primarily isolated to his dogs and his case. There was a movement away from using "pit bull" as a negative description, but the lack of coverage of other dogfighting raids, and the fact that pit bull-type dog advocacy stories were exclusively written in context of the Vick case, implies the media are solely interested in covering these topics when there is a famous person involved or a dog described as a "pit bull" attacks someone.

The raid on Vick's property was only one of 216 dogfighting busts occurring between April 25, 2007 and April 25, 2008 (The Humane Society of the United States [HSUS], 2008). None of the other raids were covered in the sources examined. The constant coverage of the Vick case might have given animal advocates hope that the issue of dogfighting was moving to the forefront, giving these dogs a chance to be seen as more often the victim instead of perpetrator. However, the findings of this research indicate coverage was limited almost entirely to Vick's dogs.

There were a total of 114 articles written about Vick's involvement in dogfighting found in USA Today and The New York Times. Outside stories about his case there were six stories written about pit bull-type dogs acting aggressively. There were no stories covering the other 2,190 plus pit bulls confiscated in dogfighting raids the same year as Vick's arrest (HSUS, 2007). Fifty-four of those dogs were found dead when authorities arrived, some still chained to trees, some found with duct tape over their mouths, some in trash bins (HSUS, 2007).

In the two-year time frame examined in this study, there were more than 3,383 pit bull-type dogs seized in the 310 dogfighting raids documented by The Humane Society of the United States. Almost all of those dogs confiscated while still alive were euthanized due to the lack of resources to rehabilitate and home them, but none of their stories were told in the sources examined for this study. Some of the raids involved more than 100 dogs, making them significantly larger in scale than the Vick raid (HSUS, 2006, 2007 \& 2008). Along with the thousands of living dogs, over 80 remains of dead pit bulls were discovered on the properties where the dogfighting busts occurred (HSUS, 2006, 2007 \& 2008). Based on the media coverage examined, the conclusion can be drawn that the difference in newsworthiness of a pit bull that is hung, set on fire, or held under water while being electrocuted depends upon the fame of the hands that torture, not the torture itself.

While a movement away from using "pit bull" as a euphemism for all things nefarious was noted in the results in the year directly after the Vick case, the issue of pit bull-type dogs as victims of non-famous dogfighters, other forms of 
abuse, and BSL were largely disregarded. This indicates the Vick case was more an anomaly than an indication of change in media coverage of pit-bull-type dog related stories.

\section{Limitations}

This study examined articles solely from USA Today, The New York Times and The Wall Street Journal from April 25, 2006 to April 26, 2008. Examination of a larger group of publications over a longer time frame, or publications from regional newspapers might yield different conclusions. In addition, these findings were based on print media, specifically three daily papers in national circulation, and excluded television, radio, and magazine coverage of the topic. This study focused solely on the immediate changes of coverage in the year following the Vick case. Any change occurring in media coverage of pit bull-type dogs beyond April 25, 2008 is not addressed in this study. Future studies might examine local media coverage of pit bull-type dogs or how media covered Vick's apology and involvement in antidogfighting efforts.

\section{Conclusion}

Although there was a movement away from using the term "pit bull" as a negative description immediately after the Vick case, this research shows print media treatment of pit bull-type dogs not belonging to Vick remained virtually unchanged during the period examined. Considering the absence of coverage of other dogfighting raids involving thousands of abused pit bulls not belonging to celebrity owners, when compared to the excessive coverage of the Vick case, a conclusion can be drawn that pit bull-type dogs and the many issues surrounding them, are often only deemed newsworthy if they bite or suffer at the hands of someone famous. This has contributed to a tragically negative, onedimensional portrayal of a major demographic of dogs in the United States.

\section{Special Thanks}

Special thanks to Dr. Kathy Keltner-Previs, Assistant Professor of Communication at Eastern Kentucky University and Mr. John Goodwin, Director of Animal Cruelty Policy for The Humane Society of the United States for their assistance in this study. This research is dedicated in memory of the pit bulls that suffered and died without mention.

\section{References}

A Catalyst for Change (2007, August 28). USA Today, p. A10.

Babbie, E. (1999). The Basics of Social Research. Belmont: Wadsworth Publishing Company.

Barnes, S. (2006, August 19). Texas: Judge Orders 225 Pit Bulls Killed. The New York Times.

Burrows, T.J., \& Fielding, W.J. (2005). Views of College Students on Pit Bull "Ownership": New Providence, The Bahamas. Society \& Animals, 13, 139-152.

Brantley, B. (2006, August 18). The Story of a Guy Who May Not Be Martin Short, But Sure Looks Like Him. The New York Times, p. 3.
Capp, D. M. (2004). American Pit Bull Terriers Fact or Fiction: The Truth Behind One of America's Most Popular Breeds. Phoenix: Doral Publishing.

Cohen, J. \& Richardson, J. (2002). Pit Bull Panic. Journal of Popular Culture, 36, 285-317.

Daugherty, P. (2009, July 22). Sorry, But It's Time to Let Vick Play. USA Today, p. C3.

Delise, K. (2007). The Pit Bull Placebo: The Media, Myths, and Politics of Canine Aggression. United States: Anubis Publishing.

Duffy, D. L., Hsu, Y., Serpell, J.A. (2008). Breed Differences in Canine Aggression. Applied Animal Behavior Science, $114,441-460$

Falcons' Vick Indicted by Grand Jury In Dogfighting Probe (2007, July 18). Retrieved from http://sports.espn.go.com/nfl/news/story?id=2940065

Goodman, B. (2006, May 15). After Surviving Hurricane and Being Mauled by Dog, Pony Is Still Standing. The New York Times, p. 18.

Gorant, J. (2008, December 29). Happy New Year. Sports Illustrated, p. 72, 77.

Gorant, J. (2010, October 4). Starting Here, Starting Now. Sports Illustrated, p. 16, 17.

The Humane Society of the United States. (2006). Documented Dogfighting Raids.

The Humane Society of the United States. (2007). Documented Dogfighting Raids.

The Humane Society of the United States. (2008). Documented Dogfighting Raids.

In Handling Abuse Cases, the NFL Mirrors Society (2007, September 6). USA Today, p. A12.

Jones, C. (2006, September 4). Law Address Dogs' Potential for Danger. USA Today.

Jacobs, A., \& Baker, A. (2006, July 25). No Rules Broken in Shooting of Attacking Pit Bull in Bronx, Police Say. The New York Times, p. B5.

Koch, W. (2007, August 30). Dogfighting Raids Climb After Vick. USA Today, p. A1.

Kuczynski, A. (2006, 7 September). Critical Shoppers; Exploring the Great Indoors, Late at Night. The New York Times.

Lee, S.A., Gibbons, J.A., \& Short, S.D. (2010). Sympathetic Reactions to the Bait Dog in a Film of Dog Fighting: The Influence of Personality and Gender. Society \& Animals, $18,107-125$.

Liebovich, M. (2006, July 11). Pit Bull of the House Latches On to Immigration. The New York Times, p. A1.

Macur, J. (2008, February 2). Given Reprieve, N.F.L. Star's Dogs Find Kindness. The New York Times, p. A1.

Mihoces, G. (2007, July 30). Vick Co-Defendant Working Deal; Nike Contract on Hold. USA Today, p. C7.

Meltzer, D. (2006, December 29). Their House Is A-Rockin', But Do Come A Knockin'. USA Today, p. D4.

Mr. Electric: Why Michael Vick of Virginia Tech Has Sparked A Revolution at Quarterback (2000, August 14). Sports Illustrated. Retrieved from http://sportsillustrated.cnn.com/vault/cover/featured/975 3/index.htm 
Olsen, K. P., Levy, J.K., Norby, B. (2012). Incorrect Breed Identification Costs Dogs Their Lives. Maddie's Shelter Medicine Program. Retrieved from http://www.maddiesfund.org/Maddies_Institute/Articles/ Incorrect Breed Identification.html

Penalties Are More Severe (2007, July 27). USA Today, p. C10.

Pit Bull Bites Officer (2006, July 26). The New York Times.

Roberts, S. (2007, June 6). In Sports, Unleashing the Dogs That Abhor. The New York Times.

Saraceno, J. (2007, January 1). Normal Guy Tank Gives Critics Lots of Ammunition. USA Today, p. C6.

Sandomir, R. (2007, August 1). In Endorsements, No Athlete Is a Sure Thing. The NewYork Times, p. D5.

Santos, F. (2006, July 24). 4 Officers Hurt (One by Pit Bull) as Police Fire 26 Shots to Kill Dog in Bronx. The New York Times, p. B3.

Schmidt, M.S. (2007, August 1). In the Case of Vick, Dogs Are Held as Evidence. The New York Times, p. D1.

Sullivan, J. (2006, November 23). Man Admits Mistreating Pit Bulls. The New York Times.
Swift, E.M. (1987, July 27). The Pit Bull Friend and Killer. Sports Illustrated. Retrieved from http://sportsillustrated.cnn.com/vault/article/magazine/M AG1066224/index.htm

Twining, H., Arluke, A., Patronek, G., (2001). Managing the Stigma of Outlaw Breeds: A Case Study of Pit Bull Owners. Society \& Animals, 8, 25-52.

Urbina, I. (2007, July 23). States Try to Weigh Safety With Dog Owners' Rights. The New York Times, p. A12.

Vitello, P. (2006, October 15). Helping the Disadvantaged, A Suffering Pet at A Time. The New York Times.

Weingarten, R., (2009, July 24). Take A Pass. USA Today, p. A12.

Weisman, L. (2007, August 21). Memories Still Haunt Ferguson. USA Today, p. C2.

Whitaker, B. (2006, September 10). Pit Bull Owners Put Laws to the Test. The New York Times, p. L14.

Whoopi Goldburg Defends Vick On 'The View' (2007, September 4). Associated Press. Retrieved from http://www.foxnews.com/story/0,2933,295718,00.html 